\title{
Leena Palotie-Peltonen, 1952-2010, visionary and role model
}

\author{
Gert-Jan van Ommen ${ }^{1}$
}

European Journal of Human Genetics (2010) 18, 624-625; doi:10.1038/ejhg.2010.58

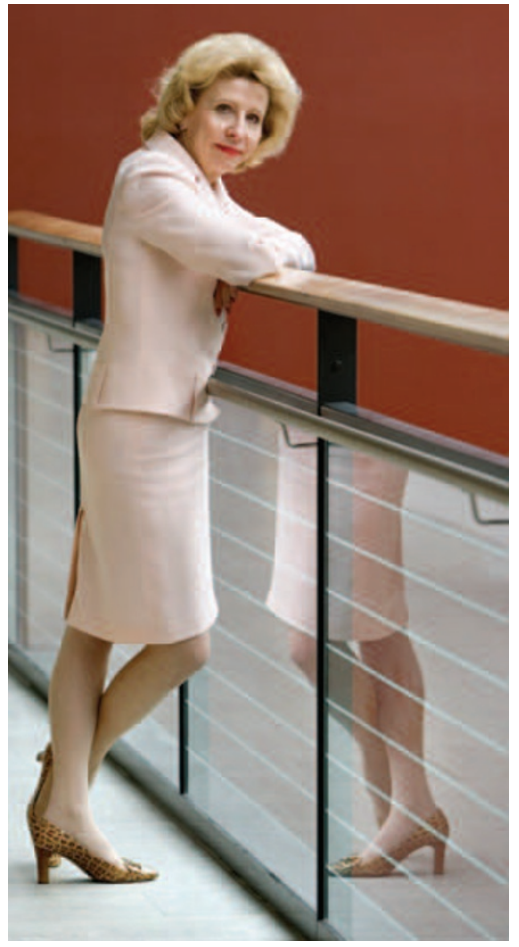

On 11 March 2010, the scientific community lost a cherished member and great inspirator with the passing of Professor Leena PalotiePeltonen, at home, in the care of her family, at the age of 57, following a brave 2-year battle with bone cancer.

Leena Peltonen has been a key player in human molecular genetics, from the early days of Human Gene Mapping, and has been involved in mapping genes and finding mechanisms underlying rare diseases, to the first mappings of familial versions of common disorders. Ultimately she became a charismatic spokeswoman of association studies and mechanistic analysis of genes and risk factors of common diseases such as diabetes, obesity, heart disease, MS and psychiatric disorders. She is the author of over 600 papers and enjoyed great pride in science and public education, leaving an invaluable legacy to medical genetics by mentoring over $70 \mathrm{PhD}$ students, over 50 of which are $\mathrm{MD} / \mathrm{PhDs}-$ with another 15 still to come. She taught at numerous international institutions, including the European School of Medical Genetics when it was still in Sestri Levante, and she set up countless international
$\mathrm{PhD}$ and postgraduate networks as a part of Finnish, Nordic, European and transatlantic consortia and centres of excellence.

Leena Peltonen started her career in Oulu, did her postdoctoral at Rutgers University, New Jersey, and returned to the National Institute of Public Health in Helsinki, becoming a professor at 39 years in 1991. Her main focus was the 'Finnish Disease Heritage', a group of ca. 40 rare recessive diseases including inborn errors of metabolism, collagen disorders, skin and eye diseases, enriched in Finland due to its unusual demographics: small groups of settlers, carrying limited sets of rare mutations, who populated 2000 years ago, as she would say, 'the edge of the inhabitable world'. She has elucidated the causative genes and mechanisms behind two dozen of these, and assisted with finding the rest. This has allowed proper screening and counselling for those patients and families afflicted with these diseases, but ironically and to her disappointment, her very Finland lacks such a programme as yet.

Leena Peltonen was a tireless ambassador of genetic studies in population isolates. Her vision and flamboyance, raising and employing public awareness to the special field named 'Finnish genetics', has helped in developing Finland as one of the most advanced places worldwide in human medical genetics. She was appointed Finnish Academy Professor in 2003 and awarded the title Academician of Science in 2009.

As molecular genetics tools gained more and more power in the late ' 80 s, she joined forces with other innovators like Eric Lander (Cambridge, MA, USA), in attempting to track genes for common diseases, first through forms segregating in families. Leena's team booked one of the first successes, finding an osteoarthritis gene in 1989. This heralded the hunt for risk factors in common diseases by association studies, which took a long time to begin but ultimately paid off in the first decade of the new millennium, when several dozen of risk factors were discovered in 2005-2008 using SNP chips of ever-increasing density.

Spurred by the fierce debate during the 90 s on the utility of isolate studies to find common disease factors, she hedged her bets. While pursuing the isolate approach, she also stepped up her involvement in worldwide biobanking in outbred populations. In 2002, her 'GenomEUtwin' project, uniting the twin registries of eight European countries, was the first EU-funded integrated project ever and kick-started the European recognition for large-scale genetics. In 2003, GenomEUtwin, the Canadian CARTaGENE biobank led by Bartha Knoppers (Montreal) and the Estonian biobank led by Andres Metspalu (Tartu), founded $\mathrm{P}^{3} \mathrm{G}$, the Public Population Project in Genomics, which now unites over a dozen large biobanks worldwide. She was also one of the initiators of the European Biobanking and Biomolecular Resource Infrastructure (BBMRI), led by Kurt Zatloukal 
(Graz), which has now united 52 participants and 150 associated members and is one of the most successful Life Sciences Infrastructures on the European ESFRI Roadmap. Finally, based on the success of genome-wide association studies (GWAS), she started an EU consortium, ENGAGE, together with Mark McCarthy (Oxford), collating 100000 European samples with available GWAS data for association studies of metabolic traits. This 'harnessing existing power by connecting people with data' was a tremendous success: the January and March 2009 issues of Nature Genetics were perceived by the ENGAGE community as 'their' issues.

Her interest in complex genetics went beyond just mapping. In 2002, her team unravelled the mechanism of lactose intolerance, suggesting (as was later confirmed) that this was actually the 'wild type' of the human species, while lactose tolerance is an emerging property of our ancestors following increased availability of dairy milk. In 2004/2005 her team found the link between USF1 gene variants and insulin resistance, underlying familial combined hyperlipidaemia. She was particularly proud of these findings as in both cases the variants altered the enhancer function, suggesting a fundamental mechanistic difference between the primary gene defects of typical Mendelian disease and the more subtle, regulatory alterations underlying complex disease.

Firmly rooted in the European scientific community, she was an outspoken voice on science policy in Brussels and elsewhere, and a member of the European Research Council. Yet she was also a true world citizen. She received prominent honours worldwide, including the Anders Jahre, Mauro Baschirotto, Margaret Putman, Fernstrom and van Gysel Prizes and the Carter medal. She was the President of ESHG and HUGO, member of the UNESCO Bioethics Committee and of the boards of the European and American Societies of Human Genetics. She alternated her career in Finland with distinguished missions abroad: she founded and led the UCLA Department of Human Genetics from 1998 to 2002, was Visiting Professor at the
Broad Institute and became Head of Human Genetics of the Wellcome Trust Sanger Institute in 2007, where she gave a great push to ambitious initiatives such as the 1000 genomes project and other sequence-based biology endeavours, of which science and society will reap the fruits during the coming decades.

Then fate struck, and only few in the field can't remember when, where and how they learned of Leena's illness. All her communities then witnessed her incredible strength as she maintained her unique blend of focus, humour and low nonsense tolerance, continuing to lead meetings, guide students and juggle telephone conferences, cutting to the chase till the very end.

In her, we lost a great soul mate and a fellow warrior against scientific or social ignorance, laxity and pomp. She made things happen, in her own ruthlessly charming way, enlisting those surrounding her in capacities they didn't know they had. She could be fiercely competitive and rarely lost a fight - and not for never picking one. For her last fight she made her molecular genetics colleagues worldwide tackle her cancer genome with the molecular tools of today. Even when it became clear that this battle could not be won, she wanted her field to go on to win the war, using the tools of tomorrow.

Our thoughts are with her family, her children Laura and Kristian, and her husband in a 30-year marriage, Aarno Palotie, who was also her close collaborator and inseparable conduit, shoring up her last period of hardship with relentless dedication. We will sorely miss Leena's drive, radiance and spirituality, but will fondly remember her unimitable style: how the Helsinki HUGO attendees were treated on a black conference bag with white polka dots; how this brightly dressed, chic lady could kick out her high heels and mount a chair to address the troops; or how - used to scribbling a flower next to her signature - she resolved the poor graphical powers of email by signing 'Leena (flower)'.

With her passing, the world has gotten emptier. It is up to all of us to make good on her legacy: in not just going after name and fame, but joining forces to strive for real medical utility. 